\title{
EDUCAÇÃO AMBIENTAL: UM CAMINHO POSSÍVEL PARA A CONSTRUÇÃO DE UM PROJETO SOCIETÁRIO SUSTENTÁVEL?
}

\author{
Silvana Cassia Hoeller ${ }^{1}$ \\ Maurício Fagundes ${ }^{2}$
}

Resumo: Este artigo tem a intencionalidade de refletir sobre os caminhos para a construção de um projeto societário sustentável por meio da Educação Ambiental Popular. Este estudo se constitui em um ensaio bibliográfico. O texto faz um breve resgate histórico dos principais descaminhos e possíveis caminhos para a reorganização produtiva de nossa sociedade com a inclusão de dados constituintes do atual cenário pandêmico e do panorama ambiental e educacional. Por fim, apresentamos uma proposição de Educação Ambiental Popular. Como resultado, entendemos ser possível a construção de uma sociedade sustentável se, epistemologicamente, construirmos processos de Educação Ambiental Popular, de inspiração freireana.

Palavras-chave: Educação Ambiental Popular; Pedagogia Freireana; Sociedade Sustentável.

Abstract: This article has the intention to reflect on the ways to build a sustainable societal project through popular Environmental Education. This study is a bibliographical. The text provides a brief historical overview of the main problems and possible directions for the productive reorganization of capitalist society. We also present considerations of the current pandemic scenario, with contextualizing elements of the contemporary environmental and educational panorama. The final considerations, we venture to propose Popular Environmental Education. As a result, we understand that it is possible to achieve a sustainable society if, epistemologically, we build processes of Popular Environmental Education, based on Freire.

Keywords: Popular Environmental Education; Freirean Pedagogy; Sustainable Society.

1 Universidade Federal do Paraná. E-mail: silvanahoeller@gmail.com

2 Universidade Federal do Paraná. E-mail: mauriciovitoriafagundes@gmail.com 


\section{Introdução}

Vivemos contemporaneamente um momento marcado por 'situaçõeslimites', categoria freireana que nos ajuda a refletir sobre nosso papel social e político, enquanto educadores ambientais e sujeitos que têm a vocação ontológica de 'ser mais'.

Uma das situações-limites de hoje é a Covid-19, que se manifesta de forma pandêmica. Nosso desafio é superá-la. Porém, o grande risco que corremos é tentar dar respostas imediatas, voluntaristas, a esta situação-limite, ou a qualquer outra que se apresente.

As pessoas que constituem os grupos econômicos desejosos da permanência deste projeto societário excludente nos apresentam estas situações-limites como tarefas a serem cumpridas para voltar à normalidade. Aqui já deveríamos nos perguntar, queremos essa normalidade excludente e que devasta nosso Planeta? Se não nos questionarmos, corremos o risco do fatalismo.

Estas situações-limites nos são apresentadas como determinantes históricas, incontestáveis, como se não houvesse outra opção senão a resignação e o desenvolvimento de ações pontuais para a nossa sobrevivência. O risco é ficarmos nas respostas, que, indubitavelmente, são necessárias para continuarmos vivos, mas é necessário o olhar crítico para entendermos suas determinações históricas e econômicas. A partir desse olhar crítico, é possível caminhar na construção de inéditos-viáveis, expressão freireana que explicita a necessária ação libertadora que vamos construindo nos processos vividos, por meio da ação crítica, como superação das situações-limites.

Seguindo essa lógica freireana, desenvolvemos nosso ensaio bibliográfico, que tem por objetivo refletir sobre os caminhos possíveis para a construção de um projeto societário sustentável por meio da Educação Ambiental Popular.

O texto principia com um breve resgate histórico dos descaminhos e possíveis caminhos da reorganização produtiva da sociedade capitalista, tomando como referência o pós-Segunda Guerra Mundial, em diálogo com autores que possibilitam uma compreensão das contradições referentes ao desenvolvimento de nosso projeto societário, para então, projetar ações e propostas consistentes que viabilizem a construção de inéditos-viáveis, como possibilidade de melhor qualidade de vida para todos.

Também estão incluídos dados constituintes do atual cenário pandêmico, com elementos de contextualização do panorama ambiental e educacional da contemporaneidade.

Antes das considerações finais, ousamos na proposição de caminhos para a construção de um projeto de sociedade sustentável, por meio da Educação Ambiental Popular, com aporte teórico na obra freireana e na categoria cultura e educação popular.

Revbea, São Paulo, V. 15, № 5: 213-229, 2020. 


\section{Alguns elementos históricos dos descaminhos aos possíveis caminhos}

Descaminhos é um termo utilizado por Porto Gonçalves (2006) no livro em que analisa e busca projetar pistas sobre as raízes da devastação das nossas condições de vida. Com esta inspiração, buscaremos algo bem mais simples, porém não menos importante, que é reapresentar alguns fatos de nossa história recente, principalmente do pós-Segunda Guerra Mundial, que em muito tem contribuído para a construção dos descaminhos no Brasil.

Com a Segunda Guerra Mundial, houve um fenômeno da concentração e centralização das riquezas, um processo que fortaleceu o sistema de monopólio. Houve, nesse aspecto, um fortalecimento dos Estado Unidos, sobre os países que diretamente sofreram prejuízos com a guerra. No Brasil, isso "provocou mudanças de hábitos e costumes, padrões de comportamento, consciência e linguagem" (BANDEIRA, 1978, p. 309). Na agricultura, esse reflexo estava presente na adoção do pacote tecnológico, que incluía máquinas agrícolas, sementes melhoradas, adoção de monoculturas, adubos, venenos e empréstimos bancários. O resultado desse processo concentrou-se na aceleração do êxodo rural e na ampliação das fronteiras agrícolas para a produção da monocultura de exportação, em detrimento do meio ambiente.

Entre as décadas de 1960 e 1970, a população rural caiu de 48\% para $26 \%$. Houve avanço da urbanização dos grandes centros, que passaram a abrigar os sujeitos que buscavam alternativas de vida. No ambiente rural, a agroindústria da cana-de-açúcar ganhou espaço, com a expansão do capitalismo no campo.

Desse modo, o camponês perdeu a terra em que trabalhava, pois não possuía os recursos necessários para se manter no campo. Consequentemente, a população rural deslocou-se para os centros urbanos, na tentativa de encontrar trabalho e qualidade de vida. O período histórico foi marcado pelo avanço da revolução verde, ou seja, a agricultura que se industrializou. Esse período foi retratado por Raquel Carson (1962) como o momento em que o ser humano adquiriu um poder de modificação da natureza, principalmente a contaminação do ar, da terra, dos rios e do mar, com materiais letais à vida. $\mathrm{O}$ ser humano "desfaz o controle e o equilíbrio através dos quais a natureza mantém a espécie dentro de um equilíbrio" (CARSON, 1962 , p. 26). Consequentemente os produtos químicos encontram-se na estrutura dos seres humanos e da natureza, proporcionando a poluição de rios, solos, contaminação genética e diminuição da biodiversidade.

No que diz respeito à educação desenvolvida a partir do pós-Segunda Guerra Mundial, estava ligada diretamente à proposta econômica capitalista, que tinha como modelo a economia dos Estados Unidos. Além de modelo, sofria forte influência econômica, por meio dos processos de financiamento, como por exemplo o acordo conhecido como a Aliança para o Progresso, MECUSAID de 31/03/65 - Acordo MEC-Contap (Conselho de Cooperação Técnica da Aliança para o Progresso) (CUNHA; GOES, 1985). 
A Aliança para o Progresso projetava ações em todos os níveis da educação escolar brasileira. O caráter educacional proclamado era de um ensino técnico e de subordinação política, pois no pós-Segunda Guerra vivia-se o momento denominado guerra fria, em que na ótica americana, havia necessidade do exercício de um forte controle, sob pena do Brasil aderir ao comunismo. A proposta era de formar mão de obra para acelerar o projeto de desenvolvimento, fundamentado na devastação do ambiente, como nos lembra Porto Gonçalves (2006).

Ainda descrevendo os impactos dessa proposta de desenvolvimento capitalista sobre o meio ambiente, relembramos o processo de erosão genética, que está relacionado à Revolução Verde, destacada por Mooney (1987), em seu livro 'O escândalo das sementes', denunciando o envolvimento da indústria agroquímica atrelada ao pacote de sementes e insumos, juntamente com a lei de patentes de variedades. $O$ autor, nesse trabalho, mostra que dos 500 tipos de vegetais cultivados em mil anos no mundo, estamos comercializando apenas 80 vegetais. $E$ destes, apenas 20 representam $90 \%$ da dieta humana: trigo, arroz e milho correspondem a $75 \%$ deste consumo. Houve eliminação da diversidade em favor da maior produtividade, que está refletida na uniformidade genética, tornando as plantas suscetíveis a desequilíbrios representados por insetos e doenças.

Com a industrialização da agricultura, a demanda pela água cresceu, motivando a retirada direta desse recurso dos rios e a construção de poços que resultaram no rebaixamento do lençol freático, caminhando para um esgotamento dos aquíferos.

No final da década de 1990, assistimos uma corrida genética representada pelos transgênicos, que foram o resultado da modificação genética com o intuito do aumento da produtividade, aspectos nutricionais e resistência. As plantas transgênicas assolaram os mercados de sementes, colocando primeiramente em risco a autonomia dos povos tradicionais, na relação com o patrimônio genético que são cultivados há centenas de anos por essas populações. A contaminação genética entre plantas é o fator principal de risco e de preocupação. Os impactos ambientais, biológicos e na saúde das gerações dos seres humanos não foram avaliados.

Começaram a aparecer contratos de bioprospecção com o propósito de vender a preços altos o acesso à biodiversidade, principalmente de florestas tropicais, mas que dão acesso a bancos genéticos de grande interesse às empresas comerciais. Alguns autores argumentam que a bioprospecção é melhor que a biopirataria, pois existe uma remuneração com uma certa regulamentação. De acordo com Alier (2017, p. 198), "a indignação quanto à biopirataria na agricultura resulta do inconformismo pelo fato de que as variedades de cultivo e o conhecimento camponês são considerados de livre acesso" e atualmente as sementes melhoradas e transgênicas são patenteadas. 
Existe uma diversidade genética vasta entre plantas cultivadas que foram 'ignoradas' pela indústria de produção de semente e que pode estar ameaçada a desaparecer devido às contaminações, como por exemplo, a produção de milho crioulo que é preservado pela população camponesa e tradicional, mas está em risco de extinção.

Os grãos se converteram em um dos pilares da economia brasileira, que vinculada à americana, pelo agronegócio, constituem as empresas de domínio do setor, estabelecendo relações mundiais. O centro da alimentação humana depende exclusivamente dos grãos. Houve uma redução da diversidade alimentar, que está sendo orquestrada, principalmente pelo interesse mercadológico e de acesso.

Até aqui recuperamos alguns elementos dos descaminhos. A partir de agora, iremos elencar alguns movimentos, produzidos socialmente, que têm procurado reconstruir caminhos que possam nos conduzir a uma sociedade democrática, carregada da ética da valorização da vida de todos e todas pessoas e espécies.

Acerca da educação, tem destaque o caráter tecnicista e de uma formação direcionada para o mercado de trabalho, demarcado, naquele momento, pela necessidade da criação de novas habilidades para atender a indústria e a agropecuária, que passavam por um processo de modernização. Essa era uma das proposições definidas naqueles anos do pós-Segunda Guerra Mundial, pela força hegemônica dos Estados Unidos.

Porém, como a história é um processo dialético e não linear, nesse período, no Brasil, algumas forças se aglutinavam em torno da Igreja Católica criando o Movimento de Educação de Base, o MEB. A proposta do MEB era alcançar a grande maioria da população que não havia acessado a escola ou havia tido a necessidade de deixá-la em segundo plano em virtude da situação de pobreza. O princípio que orientava o MEB fundava-se em ações educativas transformadoras da consciência nacional, que instrumentalizasse seus sujeitos a ações político-sociais, possíveis de contribuir para a formação de um novo projeto societário.

Nesse mesmo período, e no bojo de um movimento contrahegemônico, desenvolvia-se, também, um processo de questionamento sobre os modos de ser brasileiro, de sua cultura. Pretendia-se "um projeto político que possibilitasse superar a dominação do capital sobre o trabalho e, em decorrência, reformular tudo o que dessa dominação decorre" (FÁVERO, 1983, p. 8). Com essa intencionalidade, ampliam-se os círculos de discussão, envolvendo das ligas camponesas às universidades. $O$ autor enfatiza que o objetivo era transformar a cultura brasileira e, por meio dela, "transformar a ordem das relações de poder e da própria vida do país" (1983, p. 9).

Envolvidos nessa proposta, tínhamos grandes expressões como: Paulo Freire, Anísio Teixeira, Fernando de Azevedo, Lourenço Filho, Almeida Junior e outros. 
Nesse contexto, Paulo Freire desenvolveu e coordenou, em 1963, a proposta de alfabetização de adultos, em Angicos, no Rio Grande do Norte. Essa proposta nada mais era do que a base de sua proposição para um sistema de ensino, que iniciaria com a educação infantil até o ensino superior. Defendia uma educação vinculada à vida, em que a leitura do mundo antecedia a leitura da palavra. Buscava a palavra rica de realidade e de experiências, aquela em que o educando(a) vai construindo sua consciência, indispensável à construção de uma sociedade democrática e, portanto, baseada na ética da vida e da existência (FREIRE, 2001), dando corpo aos conceitos de cultura e educação popular.

Por ser uma proposição de caráter revolucionário, como diria Chico Buarque na canção Roda Viva: "a gente quer ter voz ativa, no nosso destino mandar, mas eis que chega a roda viva e carrega o destino prá lá...", o golpe militar de 1964 (a roda viva) interrompeu este e outros movimentos emancipatórios, que puderam ser retomados somente na década de 1980. Porém, o abafamento dessas proposições, durante o regime militar, só fez acentuar a degradação das condições de vida das pessoas e do meio em que viviam e vivem.

Em 1972, as Nações Unidas organizaram a Conferência de Estocolmo, cujo título era muito significativo, pois colocava na mesma frase o humano e o ambiente, "Conferência das Nações Unidas sobre o meio ambiente humano". Ficou reconhecida como um marco histórico por problematizar a necessidade de melhorar as relações do homem com o meio ambiente, propondo equilíbrio entre o desenvolvimento econômico e a redução da degradação ambiental. Porém, nada disso chegou ao processo de educação que se desenvolvia no Brasil, nessa época.

No final da década de 1980 a Comissão Mundial do Ambiente e do Desenvolvimento - WCED (BRUNDTLAND,1987), produziu um relatório, para direcionar uma agenda de mudanças globais, proveniente de uma solicitação da Assembleia Geral das Nações Unidas, em que o meio ambiente estava no cerne das decisões políticas e era necessário um comprometimento das nações envolvidas.

Uma das problemáticas do relatório da WCED foi a questão das interferências humanas nos sistemas naturais no decurso do desenvolvimento. O relatório enfatiza que "no mínimo, é preciso que o desenvolvimento sustentável não ponha em risco os sistemas naturais que servem de sustentáculo ‘a vida na terra [...]” (BRUNDTLAND, 1987, p. 56).

Também é importante considerar que temos a simplificação dos ecossistemas e a redução da diversidade na relação com o desenvolvimento, ou seja, "o desaparecimento de espécies vegetais e animais pode limitar grandemente as opções das futuras gerações [...]" (BRUNDTLAND,1987, p. 57). 
Vinte anos após a Conferência de Estocolmo, no ano de 1992, o Brasil sediou a Conferência das Nações Unidas sobre o Meio Ambiente e o Desenvolvimento, que ficou conhecida com a Eco-92, Cúpula da Terra, Cimeira do Verão, Conferência do Rio de Janeiro e Rio 92. Foi um evento que reuniu 178 países com o objetivo de construir ações para diminuir a degradação ambiental. Outro objetivo, a criação de medidas para garantir a existência das futuras gerações, mais do que proposição, foi a revelação de que nesse ritmo de destruição da natureza, a civilização sucumbirá.

Outro grande mérito desse evento foram as muitas produções como: a Carta da Terra, a Declaração de Princípios sobre as Florestas, a Agenda 21, a Declaração do Rio sobre Meio Ambiente e Desenvolvimento, a Convenção sobre Diversidade Biológica e a Convenção das Nações Unidas de Combate à Desertificação. Decorrente dessas produções coletivas, muitas se transformaram, no Brasil, em políticas públicas, inclusive na área da Educação Ambiental, como por exemplo a Política Nacional de Educação Ambiental PNEA (BRASIL, 1999).

O PNEA reconhece em seu texto a interdependência entre os seres humanos e a natureza, expresso em seu Artigo 1․:

Entendem-se por Educação Ambiental os processos por meio dos quais o indivíduo e a coletividade constroem valores sociais, conhecimentos, habilidades, atitudes e competências voltadas para a conservação do meio ambiente, bem de uso comum do povo, essencial à sadia qualidade de vida e sua sustentabilidade (BRASIL, 1999).

Essa proposta em processo de reconhecimento da lógica, que rompe a dicotomia entre humanos e natureza, continua a se expressar no decorrer do PNEA, porém, parece pertinente destacar o Art. $5^{\circ}$, que descreve os objetivos fundamentais da Educação Ambiental. Defende no inciso I: "o desenvolvimento de uma compreensão integrada do meio ambiente em suas múltiplas e complexas relações, envolvendo aspectos ecológicos, psicológicos, legais, políticos, sociais, econômicos, culturais e éticos" (BRASIL, 1999).

O PNEA segue nessa direção e no Artigo 9o refere-se diretamente à Educação Ambiental no Ensino Formal, englobando desde a Educação Infantil ao Ensino Superior.

Essa e outras políticas educacionais remetem a uma ideia de possíveis caminhos que desconstruíssem os descaminhos, parafraseando Porto Gonçalves (2006), mas o que faltou? Antes de adentrar em novas proposições e refletir sobre o que faltou, vejamos como está nossa realidade ambiental e os processos vigentes de Educação Ambiental. 


\section{Dados de nossa atualidade constituintes do atual cenário pandêmico}

O Brasil tem como base para o desenvolvimento econômico a superexploração dos recursos naturais. Agroexportamos recursos como água e nutrientes, por meio das toneladas de grãos produzidos. Existe uma monetarização do ambiente em decorrência da destruição dos ecossistemas. Além do passivo ambiental, que envolve a extração de petróleo, minérios entre outros, revela-se o que o autor Alier (2017) traz como ecologia desigual em termos dos riscos e dos danos à saúde e ao meio ambiente, em que as exportações não agregam as externalidades negativas ao ambiente. Somos produtores de matérias-primas exportadas dos países da região Sul, voltadas para o pagamento da dívida externa, ou seja, existe um comércio ambientalmente insustentável.

No contexto vivido pela sociedade atual, temos o esgotamento de um modelo que estabelece uma relação fragmentada entre ser humano e natureza, em que o processo está fundamentado no mercado e não na vida. Conforme Sousa Santos (2020), existe uma separação entre os processos políticos e civilizatórios, o que prejudica a capacidade da sociedade de pensar alternativas para a relação humana com o ambiente, no sentido de frear o aquecimento global, a perda de biodiversidade entre outras.

Em janeiro de 2019, o Relatório da Comissão The Lancet (SWINBURN et al., 2019, p. 02), anunciava as três pandemias que fazem parte das estruturas mundiais, em que "Mudanças climáticas estão na iminência de entrar em um caminho sem volta, e as pandemias da obesidade e da desnutrição ameaçam a segurança alimentar da maior parte da população mundial" e coloca a necessidade de reformulação dos sistemas de alimentação, transporte, produção agropecuária, processo de urbanização e uso do solo.

Nesse mesmo caminho Azevedo (2020, p. 45), coloca a importância do papel do Estado em uma sociedade fragilizada, em que "o vírus expôs o perigo, a fragilidade, e a falácia que foilé a implementação da agenda neoliberal de redução do papel do Estado e de precarização dos serviços públicos [...]". Para o enfrentamento da Pandemia, bem como para repensar a base da sociedade e do esgotamento do meio ambiente, temos que ter uma estrutura pública fortalecida.

Foster (2020) reforça a relação entre ser humano e meio ambiente, na entrevista à revista Carta Capital, ao ressaltar que "todas as epidemias modernas podem ser atribuídas às modificações humanas das condições ecológicas". A não priorização da vida, como um todo, fica bem visível na situação de pandemia ocasionada pelo coronavírus, covid-19, que assola as relações humanas, ambientais, econômicas e sociais.

A Plataforma Brasileira de Biodiversidade e Serviços Ecossistêmicos BPBES, Pires et al. (2019, p. 68), estimou que: 
em $60 \%$ das doenças infecciosas que acometem humanos, o patógeno tenha se multiplicado ou vivido parte de seu ciclo em um ou mais organismos, demonstrando a importância da riqueza biológica na regulação dos processos infecciosos. Os ambientes ricos em espécies animais permitem ao patógeno circular por uma gama de vetores e hospedeiros, que impedem ou dificultam o ciclo de transmissão.

A degradação dos ecossistemas se apresenta como uma ameaça à saúde e ao bem-estar humano. As ameaças acabam se concretizando em níveis epidêmicos ou pandêmicos, desorganizando os aspectos econômicos, ambientais, sociais e culturais. Entretanto, é preciso considerar que o caminho da pandemia foi construído pela sociedade humana no momento de fragmentação com a natureza.

Essa situação é também fundamentada por Sousa Santos (2020, p. 6), ressaltando "que só não há alternativas porque o sistema político democrático foi levado a deixar de discutir as alternativas". A necessidade de discussão só entra em pauta na sociedade quando as crises, colapsos, desastres ambientais entre outros, imobilizam os sistemas econômicos.

Se refletirmos sobre o atual momento, descobriremos que diversas atividades exercidas na sociedade, que foram paralisadas pela pandemia, devem ser suspensas, repensadas e ao mesmo tempo substituídas.

$\mathrm{Na}$ atual conjuntura, podemos descrever algumas dessas atividades que representam, numa leitura de ambiente sustentável, a construção de caminhos para uma dimensão ecológica com o bem-estar e a saúde, integrados à natureza em uma relação harmônica. Por exemplo, as atividades que utilizam o petróleo como fonte de energia única, como os veículos de transporte de pessoas ou de cargas, poluentes no geral, como mostra a notícia do Correio Brasiliense (13/04/2020): "imagens captadas do satélite Sentinel 5P, da Agência Espacial Europeia, mostram redução do dióxido de nitrogênio em São Paulo, Rio de Janeiro, Brasília, Goiânia, Curitiba, Salvador e Belo Horizonte". O isolamento social, ocasiona a redução da poluição em grandes centros urbanos, isso impacta positivamente na saúde das pessoas que vivem nesses espaços. Mas como manter essa diminuição da poluição e a vida humana?

Isso nos remete a velha discussão de repensar as formas de locomoção, em que o transporte alternativo, como a bicicleta, seja uma prioridade dentro do planejamento urbano e da educação. Na perspectiva da redução de emissão de poluentes, que são produtos do trabalho. Nas relações de trabalho, o "home office" ou trabalho em casa é um elemento que se tornou real com a pandemia. A questão é: veio para ficar? Talvez possa-se configurar como alternativa para diminuir os deslocamentos com transporte. As relações de trabalho devem fazer parte de uma regulamentação que priorize o bemestar e a saúde dos trabalhadores. Mas dentro da lógica atual, neoliberal, da 
legislação trabalhista flexibilizada, será uma solução ou o aprofundamento de um processo exploratório?

Por outro lado, fica evidente que a manutenção da concentração absurda de veículos de transporte nos espaços urbanos, bem como a circulação de pessoas e a emissão de poluentes, provocará uma nova crise geral do sistema de saúde e novas ondas de pandemias poderão ser ainda piores.

As profissões precisam ser repensadas, ou o modelo de produção precisa ser repensado? Certo é que a concentração de pessoas e poluentes nos centros urbanos necessita ser repensada à luz das realidades locais, ligada a uma ecologia social, cultural, política, ambiental, econômica e educacional. Temos que buscar ocupações que levem em consideração os aspectos locais e globais, em que a valoração monetária da profissão seja estipulada de acordo com a contribuição para manter estruturada uma sociedade sustentável e não apenas na exploração ambiental puramente econômica.

Podemos afirmar que o consumismo de forma geral é um elemento que se torna perigoso, supérfluo e prejudicial, diferente do consumo consciente, como por exemplo, a diminuição da utilização de plásticos, o destino correto do lixo orgânico para composteiras, a reutilização de materiais, são ações que devem ser planejadas, por profissionais que tenham uma formação para essas novas necessidade de pensar na totalidade, na relação do micro com o macro, ou seja, há um enorme perigo na responsabilização do consumo individual em detrimento da produção de larga escala dos produtos a serem consumidos e as devidas responsabilizações desses produtores.

As políticas públicas que fomentarão a reorganização desse novo perfil de um conjunto de profissões, ou mesmo da produção por parte das empresas, devem ser repensadas a partir de princípios e fundamentos no compromisso com o desenvolvimento sustentável. Para tal, podemos assumir como definição de desenvolvimento sustentável aquele que "dê resposta às necessidades presentes, sem comprometer a possibilidade de gerações futuras darem resposta às delas" (BRUNDTLAND, 1987, p. 54).

Ou podemos caminhar na perspectiva da construção do inédito-viável freireano, nos desafiando a pensar e construir um desenvolvimento sustentável em concordância com Foster (2015), quando nos alerta que estamos sob uma escolha existencial. Pois no caminho em que estamos, há o risco iminente de uma catástrofe do sistema Terra. A partir desse alerta, o autor propõe que possamos,

trilhar o caminho transformador da mudança do sistema social que vise o desenvolvimento humano igualitário em coevolução com os parâmetros vitais do planeta. Este é o desafio histórico do nosso tempo: avançar com reformas radicais que se oponham à lógica do capital no presente histórico e coalesçam com uma longa revolução que construa uma nova formação social e ecológica centrada no desenvolvimento humano sustentável (FOSTER, 2015, p. 82). 
Nessa perspectiva, a Educação Ambiental rompe definitivamente com a dicotomia entre humano e natureza. Logo, as políticas públicas e ações para reativar as instituições devem permear as questões ambientais, sociais, culturais e econômicas, que possibilitam um repensar dos recursos humanos, a alimentação segura e de qualidade, o equilíbrio dos ecossistemas, o desenvolvimento imbricado as questões ambientais e a gestão do espaço urbano de forma sustentável. Nessa toada, avançamos para realizar o exercício de ousadia de propor reflexões, fundamentos epistemológicos e ações, portanto de uma práxis que auxilie na construção de uma sociedade sustentável.

Propondo caminhos para a construção de um projeto de sociedade sustentável por meio da Educação Ambiental Popular - em busca do inédito viável

Com o enunciado acima, passamos a responder a indagação do título deste artigo, pois entendemos ser possível e necessária a contribuição da Educação Ambiental para a construção de um projeto de sociedade sustentável. Evidentemente, que destacamos o verbo contribuir, por concordarmos com Freire (2000, p. 67) que "se a educação sozinha não transforma a sociedade, sem ela tampouco a sociedade muda". Junto a esse entendimento de Freire, sabemos que vivemos em uma sociedade complexa, portanto, uma única área pode contribuir muito, porém, sozinha não tem todo o poder de transformação.

Ao longo deste artigo, buscamos apresentar os distintos momentos e movimentos constitutivos de nossa história recente, que desemboca na situação de pandemia que vivemos hoje.

Fica evidente que, em oposição ao modelo neoliberal hegemônico, foram construídos fóruns para discutir alternativas para uma sociedade sustentável desde o cenário mundial ao local. Decorreram desses fóruns, propostas que se transformaram em políticas públicas, principalmente para a área da Educação Ambiental.

A partir dessas constatações, poderemos indagar, o que faltou? Por que não se efetivaram as mudanças previstas nas legislações? Evidentemente, que são muitas as respostas possíveis, porém, vamos assumir a perspectiva epistemológica freireana, para refletir além das denúncias e rumar para possíveis anúncios.

A reflexão que propomos principia no modelo educacional vigente em nosso país. É o que Freire (2001), desde os seus primeiros escritos, denunciava como o principal problema de nossa educação, ou seja, o ensino bancário, decorrente de ações superpostas ao povo, por dirigentes, em todos os níveis, desde o governamental ao docente na escola. Nesse processo o sujeito congnoscente é o proponente e o estudante, o trabalhador, é o objeto 
que sofre a ação de um pensar que não é o dele, por mais ilustrado e bem intencionado que seja. A educação bancária é para Freire (1987, p. 59),

um ato de depositar, transferir, de transmitir valores e conhecimentos, [...] onde o educador é o que educa; os educandos, os que são educados; [...] o educador é o que pensa; os educandos, os pensados; o educador é o que diz a palavra; os educandos, os que escutam docilmente [...].

Grande parte de nossos problemas certamente não são os fundamentos epistemológicos que dão vida aos conceitos de Educação Ambiental, de sociedade sustentável e de preocupação com a vida planetária, mas o vácuo entre o processo de sua criação e o distanciamento de quem não participou dessa criação, abrindo uma grande lacuna entre o pensado e as condições concretas de sua realização, logo não conseguiu se constituir em práxis. Sua produção e instituição obedeceu a mesma lógica da educação que a antecedia, um processo idealizado, embora cheio de fundamentos revolucionários, porém formulado por elites pensantes para ser aplicado ao povo, que muito pouco ou nada participou desses processos.

A partir dessa constatação, buscamos em Freire, fundamentos em sua pedagogia para pensar caminhos. De forma sistematizada, Freire, no ano de 1959, ao prestar concurso para Universidade do Recife, escreveu uma tese sobre a Educação e atualidade brasileira, que mais tarde foi publicada na forma de livro. Nesses escritos denunciava que o problema da educação brasileira residia no descolamento da cultura popular, pois a "educação em grande parte, ou quase toda, era fora do tempo e superposta ao espaço ou aos espaços culturais do país. Daí a sua inorganicidade. A sua ineficiência [...]" (FREIRE, 2001, p. 79).

A proposição de Freire para transformação dessa realidade era fundamentada em uma escola vinculada à vida, por meio da leitura da palavra como resultante da leitura da realidade, portanto, um processo de construção da consciência, por meio da reflexão do vivido e das relações estabelecidas no meio social. Nessa perspectiva, a participação do povo de modo geral, dos educandos e educadores nos projetos de Educação Ambiental é um movimento indispensável à construção do processo democrático.

A construção de um processo de Educação Ambiental para que se efetive em práxis, exige que se ultrapasse o verbalismo e a superposição à sua comunidade. Há a necessidade "de revisão do nosso processo educativo, de que surja do seu enraizamento na realidade local, ampliando aos planos regional e nacional' (FREIRE, 2001, p. 81). Nessa proposta, o caminhar irá permitir conhecer o caminho que se quer construir, aí ultrapassamos o verbalismo, fazendo a construção de nosso discurso a partir de nossas ações, possibilitando novas atitudes frente a velhos e novos problemas. Nos alerta 0 
autor que nosso desafio, enquanto escola e enquanto educadores, reside na superação de nossa "inexperiência democrática, através de uma educação para a democracia, numa sociedade que se democratiza" (FREIRE, 2001, p. 87), portanto, a construção da práxis de um processo de Educação Ambiental só acontecerá por meio da experiência democrática.

A marca da proposta freireana é a inversão do ponto de partida, quando comparado à educação dita tradicional. A proposta de educação freireana não se dá do alto para baixo, de forma vertical, do mais ilustrado para o menos ilustrado, mas dos sujeitos que em comunhão refletem sobre suas realidades e suas situações existenciais, portanto situações carregadas de sentidos para si e para o coletivo, logo situações orgânicas explicitadas como situações-limites. Tais situações são provocativas, carregadas de conteúdo, geradoras de novos pensares e novos fazeres. Aqui reside o ponto de partida para a construção da aprendizagem que carrega consigo o processo de construção da consciência. Há a assunção das condições culturais que possibilitam a construção da democratização da escola e da comunidade (FREIRE, 2001). Nesse processo, possibilita aos estudantes e docentes refletirem sobre a sociedade opressora, sobre a dimensão da cultura do silêncio a que estão submetidos. Para então estabelecerem o diálogo com 0 sistematizado como elemento que poderá iluminar novas construções.

Nesse caminho, Freire (2001, p. 96) destaca que,

o que importa é que a escola de nossa atualidade eduque seu aluno e suas famílias no sentido da responsabilidade social e política, de que somos tão carentes ainda. Responsabilidade que só se ganha vivendo. Que só se obtém inserido em projetos onde seja ela experimentada. O que importa é que a escola de nossa atualidade, permeável e flexível, fazendo-se centro comunitário, exercite os grupos em torno dela existentes, na análise crítica da problemática local, regional e nacional.

Vejamos, parece que Paulo Freire dialoga conosco neste exato momento histórico, pois nos alerta de que não há possibilidade de construção de um processo de transformação se não for construído a partir das problematizações das populações locais, da escola como centro irradiador, avançando o diálogo com sua comunidade, para assim se servir e se apropriar de novos conceitos de Educação Ambiental. Avançar seus conhecimentos na construção dialética entre o vivido, o problematizado e o sistematizado, em uma espiral sem fim.

A proposição para superação de momentos pandêmicos, como o que vivemos hoje, passa pela construção do inédito-viável, de uma escola e de um processo de educação, que ao se construir democrática e, portanto, política, vai se libertando da escola livresca e propedêutica, transitando para uma 
escola que possa desenvolver uma Educação Ambiental "formadora de hábitos de trabalho, de participação, de crítica, de solidariedade, com que o nosso educando, desenvolvendo a sua dialogação, se integre, com autenticidade, no clima cultural que ora vivemos" (FREIRE, 2001, p. 98). Significa nos apropriarmos dos Tratados, dos resultados das Conferências Mundiais, das Leis e das Políticas Públicas, como resultado de nossas interpretações à luz de nossas realidades, portanto, apenas como instrumentos que melhor qualifiquem nossas ações e não como ditames ou prescrições que devemos sobrepor a nossa cultura e aos nossos fazeres.

Esse movimento vai constituindo o que Freire intitula de educação popular. Brandão (2012, p. 91) sintetiza esse processo como uma espécie de "passo a passo para uma nova teoria não apenas de educação, mas das relações que, considerando-a a partir da cultura, estabelecem novas articulações entre a sua prática e um trabalho político progressivamente popular", que se efetivam por meio de trocas entre as pessoas e a sociedade, criando "condições de transformação das estruturas opressoras desta pelo trabalho libertador daquele" (p. 91).

Embora esta seja uma reflexão que não termina, buscamos Brandão (2012) para sintetizar o movimento que nos parece fundante para superar momentos pandêmicos como este e, quem sabe, evitar outros. Nos referimos a passagem em que o autor nos lembra a necessidade do exercício do desapego da marca autoritária que move os egos e que, de forma geral, é uma marca original de ser do "movimento de educadores e militantes eruditos destinados a 'trabalhar como o povo', para ser um trabalho político sem projeto próprio (individual) e diretor de ações pedagógicas sobre o povo, mas a serviço dos seus projetos de classe" (BRANDÃO, 2012, p. 91). Nos parece ser esse mais um grande desafio!

\section{Considerações finais}

Nos propusemos, ao longo deste artigo, a refletir sobre as possibilidades concretas da construção de caminhos de um projeto societário sustentável por meio da Educação Ambiental.

Ao retomar os elementos históricos que têm nos trazido aos descaminhos pandêmicos, até aqui, fica evidente a percepção dicotômica entre economia e ambiente, e aqui estamos presentes. O processo de avanço da economia, por meio do modelo neoliberal, foi rompendo com o que ainda tinha de equilíbrio entre o ser humano e a natureza. A busca pelo lucro foi fomentando um tipo de exploração suicida, arrasando o meio natural e humano. O conhecimento a serviço de um processo de biopirataria na agricultura gerou miséria de variedades de alimentos, pobreza e doenças nas pessoas do campo e da cidade.

Atrelado a essa situação, vimos um processo educacional dependente 
processo linear, sem reação. A educação por meio do MEB, da cultura popular e da educação popular, demarcou uma oposição crítica a esse projeto societário (HOELLER; FAGUNDES, 2019). A Educação Ambiental, por meio da Conferência de Estocolmo, rompe com a dicotomia humano e o ambiente ao se definir como Conferência sobre o meio ambiente humano.

Como sabemos, a história é um processo dialético, portanto esse mesmo processo que teima em dominar o ambiente e o ser humano, passa a sofrer as consequências por meio das crises. Outros movimentos internos e externos se constituem no enfrentamento da agenda neoliberal. A Educação Ambiental se fortalece por meio de tratados e políticas públicas.

Chegamos ao momento da pandemia. $O$ que fazer? Diminuir as atividades que usam derivados de petróleo? Mudar os processos agrícolas de produção? Mudar os processos de trabalho? Precarizar mais? Mudar a lógica consumista? Como construir um processo de desenvolvimento sustentável? Bem, sem desconsiderar a solução individual para cada uma dessas situações, mas sempre na relação com o projeto societário que queremos, passamos a pensar em uma possiblidade que dê suporte a mudança e sua manutenção.

O que defendemos? A construção de uma Educação Ambiental com outra lógica epistemológica. Na última parte do texto, construímos argumentos em defesa de um processo de Educação Ambiental popular, pautado na pedagogia freireana. Isto significa assumir que não bastam grandes conferências, belos enunciados, importantes tratados, políticas públicas com boas conceituações. Esses eventos, apesar de fundamentais para a área, para os estudiosos e para a academia, foram produzidos sem os sujeitos de sua ação, ou seja: o povo, os estudantes, os docentes. Logo, apesar da perspectiva de ciência preocupada com o Planeta, a base epistemológica para sua implementação, apesar de ilustrada e bem-intencionada, é a mesma autoritária que muito condenamos. É construída para o povo, mas sem o povo, portanto autoritária.

Defendemos uma Educação Ambiental vinculada à vida das pessoas dos lugares, construindo caminhos, que ao lerem seus processos de realidade, conhecem, se reconhecem em um sistema opressor. Ao construírem conhecimentos por meio da ação, constroem processos de consciência de seu papel social e político em suas comunidades e com o meio em que vivem. Constroem juntos, dialogam e avançam nesse conhecimento na leitura do mundo e dos conhecimentos sistematizados. Não há superposição, não há espaço para o verbalismo, porque o conhecimento vai se produzindo enraizado em suas realidades locais. Há um processo democrático de Educação Ambiental popular.

Por fim, defendemos como caminho de fortalecimento social e político para enfrentamento e/ou superação de processos pandêmicos, a construção de uma Educação Ambiental popular, de base freireana. Se efetivando em um processo dialético onde o ponto de partida são as pessoas e suas realidades e o ponto de apoio é o conhecimento sistematizado, como possiblidade de 
avançar em novas construções que superem as estruturas opressoras por meio do trabalho libertador do povo, das escolas, dos docentes, dos discentes, como protagonistas da Educação Ambiental popular.

\section{Referências}

ALIER, J. M. O ecologismo dos pobres: conflitos ambientais e linguagens de valoração. 2. ed. $3^{\circ}$ reimpressão, São Paulo: Contexto, 2017.

AZEVEDO, Alessandro Augusto de. 0 que a pandemia interpela a professores e professoras. Natal: Editora Feitoemcasa, 2020.

BANDEIRA, M. Presença dos Estados Unidos no Brasil: dois séculos de história. 2. ed. Rio de Janeiro: Civilização Brasileira, 1978.

BRANDÃO, C. R. O que é educação popular. São Paulo: Brasiliense, 2012.

BRASIL. Política Nacional de Educação Ambiental. Lei № 9795/1999 de 27 Abril de 1999. Disponível em: https://www.camara.leg.br/proposicoesWeb/prop mostrarintegra;jsessionid=50 EE32BD99AF52EB7D5DB8E7E03AE765.node1 ? codteor $=634068$ \&filename $=\mathrm{L}$ egislacaoCitada+-PL+4692/2009. Acesso em: 20 jun. 2020.

BRUNDTLAND, G. H. O Nosso Futuro Comum - Comissão Mundial do Ambiente e do Desenvolvimento - W.C.E.D. Lisboa: Meribérica/Liber, 1987.

CARSON, R. Primavera Silenciosa. Lisboa: Ed. Portico, 1962.

CORREIO BRASILIENSE. Quarentena reduz a poluição. Disponível em: https://www.correiobraziliense.com.br/app/noticia/brasil/2020/04/13/internabrasil ,844116/imagens-de-satelite-mostram-como-a-quarentena-reduz-apoluicao.shtml. Acesso em: 25 mai. 2020.

CUNHA, L. A. e GÓES, M. O golpe na educação. Rio de Janeiro: Jorge Zahar Editora, 1985.

FÁVERO, O. (Org.). Cultura popular e educação popular: memória dos anos 60. 2. ed. Rio de Janeiro: Graal, 1983.

FOSTER, J. B. Marxismo e Ecologia: fontes comuns de uma grande transição. Lutas Sociais, São Paulo, vol.19 n.35, p.80-97, jul./dez. 2015.

FOSTER. J. B. Entrevista com John Bellamy Foster. 2020. Carta Capital. Disponível em: https://envolverde.cartacapital.com.br/capitalismo-de-catastrofemudanca-climatica-covid-19-e-crise-economica/. Acesso em: 25 mai. 2020.

FREIRE, P. Ação cultural para a liberdade e outros escritos. Rio de Janeiro: Paz e Terra, 1982.

FREIRE, P. Pedagogia do oprimido. 17. ed. Rio de Janeiro: Paz e Terra, 1987.

FREIRE, P. A educação na cidade. 4. ed. São Paulo: Cortez, 2000. 
FREIRE, P. Educação e atualidade brasileira. São Paulo: Cortez, 2001.

HOELLER, S. C.; FAGUNDES, M. C. V.; FARIAS, M. I. Educação do Campo, educação popular e a geografia: uma construção dialógica. Curitiba: Intersaberes, 2019.

MOONEY, P. R. O escândalo das sementes: o domínio da produção de alimentos. São Paulo: Nobel, 1987.

PIRES A. P. F. et al. $1^{\circ}$ Diagnóstico Brasileiro de Biodiversidade e Serviços Ecossistêmicos, BPBES - Plataforma Brasileira de Biodiversidade e Serviços Ecossistêmicos. 2019. Disponível em: https://www.bpbes.net.br/wpcontent/uploads/2019/09/BPBES Completo VF1.pdf. Acesso em: 25 maio de 2020.

PORTO GONÇALVES, C. W. Os (des)caminhos do meio ambiente. 14. ed. São Paulo: Contexto, 2006.

SOUSA SANTOS, B. A cruel pedagogia do virus. Coimbra: Almeida, 2020.

SWINBURN, B. A. et al. A Sindemia Global da Obesidade, da Desnutrição e das Mudanças Climáticas: relatório da comissão The Lancet. Jan. 2019. Disponível em: https://alimentandopoliticas.org.br/wpcontent/uploads/2019/10/Relat\%C3\%B3ri o-Completo-The-Lancet.pdf. Acesso em: 25 maio de 2020. 